\title{
Substituição de milho por sorgo baixo tanino em dietas para suínos: digestibilidade e metabolismo
}

[Replacement of corn by low tannin sorghum in pig diets: digestibility and metabolism]

B.M.F.P.P. Marques, G.B. Rosa, L. Hauschild, A.d'A. Carvalho, P.A. Lovatto*

${ }^{1}$ Universidade Federal de Santa Maria (UFSM), Santa Maria -RS

Faixa de Camobi, km 9 - Campus Universitário

97105-900 - Santa Maria, RS

\begin{abstract}
RESUMO
Um experimento foi realizado para avaliar os efeitos digestivos e metabólicos da substituição de milho por sorgo em dietas para suínos. Foram utilizados 12 suínos machos castrados, meio-irmãos paternos, com peso vivo médio inicial de 40,8kg, mantidos em gaiolas metabólicas. O delineamento experimental foi inteiramente casualizado com três tratamentos $(\mathrm{T} 1=$ dieta controle; $\mathrm{T} 2=$ substituição de $50 \%$ do milho por sorgo e T3 = substituição de $100 \%$ ) e quatro repetições. As digestibilidades da proteína e da energia brutas foram 5 e $4 \%$ superiores $(\mathrm{P}<0,05)$, respectivamente, nos suínos alimentados com a dieta que tinha $50 \%$ de substituição, comparadas àquela com substituição total do milho por sorgo. A substituição total do milho por sorgo reduziu $(\mathrm{P}<0,05)$ as digestibilidades, em relação à dieta-controle, em $3 \%$ para MS, $8 \%$ para $\mathrm{PB}$ e $5 \%$ para $\mathrm{EB}$. O N fecal foi $25 \%$ maior $(\mathrm{P}<0,05)$, o $\mathrm{N}$ absorvido $10 \%$ menor $(\mathrm{P}<0,05)$ e a excreção fecal de energia $15 \%$ maior $(\mathrm{P}<0,05)$ para a dieta com substituição total, em relação à dieta-controle. A excreção fecal de $\mathrm{N}$ e energia e a absorção de $\mathrm{N}$ são influenciadas negativamente pela substituição total de milho por sorgo nas dietas. A substituição em até $50 \%$ do milho por sorgo em dietas para suínos não influi na digestibilidade das dietas e no metabolismo dos animais.
\end{abstract}

Palavras chave: nitrogênio, energia, nutrição, ingrediente alternativo

\begin{abstract}
An experiment was carried out to evaluate metabolic and digestive effects replacement of corn by sorghum in pig diets. Twelve half brothers barrows weighing $40.8 \mathrm{~kg}$ and housed in metabolic cages in a completely randomized design with three treatments $(T 1=$ control diet; $T 2=$ replacement of $50 \%$ corn by sorghum and T3 = replacement of 100\%) with four replicates. Crude protein and gross energy the digestibilities were $5 \%$ and $4 \%$ higher $(P<0.05)$, respectively, for pigs fed $50 \%$ of corn replacement diet, in comparison with the diet where corn was totally replaced by sorghum. Total replacement of corn by sorghum diets decreased $(P<0.05)$ the digestibilities, in comparison to control diet, in $3 \%$ for DM, $8 \%$ for $C P$ and $5 \%$ for GE. Fecal $N$ was $25 \%$ higher $(P<0.05)$, absorbed $N$ was $10 \%$ lower $(P<0.05)$, and the fecal excretion energy was $15 \%$ higher $(P<0.05)$ for total substitution diet in comparison to control diet. Fecal excretion and absorption of nitrogen are negatively influenced by total replacement of corn by sorghum in the diets. Replacements of up to $50 \%$ of corn by sorghum in pig diets do not affect the digestibility diet and metabolism of animals.
\end{abstract}

Keywords: nitrogen, energy, nutrition, alternative ingredient

Recebido em 17 de novembro de 2005

Aceito em 24 de abril de 2007

*Autor para correspondência (corresponding author)

E-mail: lovatto@smail.ufsm.br 


\section{INTRODUÇÃO}

O milho é o cereal mais importante na alimentação animal. Sua disponibilidade comercial e qualidade nutricional justificam sua utilização como o principal ingrediente nas dietas para suínos. Em algumas regiões brasileiras, a disponibilidade de milho, principalmente na entressafra, é insuficiente para atender à demanda humana e animal. Isso contribui para uma elevação dos preços do milho, afetando a cadeia produtiva animal. Para evitar essa situação, vários alimentos alternativos têm sido estudados, dentre os quais o sorgo, que pode ser uma estratégia para manutenção da suinocultura em regiões com maior escassez de milho.

O sorgo é o segundo cereal em importância para a alimentação de suínos no Brasil. O seu cultivo é interessante, pois é mais resistente ao estresse hídrico e menos exigente em fertilidade do solo que o milho (Lopes, 2004). O custo de produção do sorgo é cerca de $20 \%$ inferior e seu valor biológico alcança $95 \%$ do milho (Fialho et al., 2002). O sorgo tem níveis mais elevados de proteína bruta, mas menos extrato etéreo e energia que o milho (Nutrient..., 1998).

A variabilidade da composição química e conseqüentemente do valor nutricional do sorgo pode reduzir o desempenho de suínos em crescimento. A presença de fatores antinutricionais, como os taninos, pode afetar negativamente a digestibilidade das dietas (Mariscal-Landín et al., 2004). Do ponto de vista químico, no trato digestório, os taninos se combinam com proteínas reduzindo a digestibilidade (Asquith e Butler, 1986). O tipo de proteína e sua distribuição no endosperma dos grãos de sorgo são fatores que podem influenciar a digestibilidade da proteína e do amido (Duodu et al., 2003). No entanto, a utilização de sorgo de baixo tanino não compromete significativamente a utilização digestiva dos componentes da dieta e o desempenho de suínos na fase inicial (Cousins et al., 1981).

Nas últimas décadas, a evolução da genética do sorgo foi rápida, influenciando a digestibilidade dos nutrientes do grão. No entanto, as pesquisas de inclusão de novos materiais genéticos de sorgo nas dietas para suínos não acompanharam a evolução genética da cultura, sendo necessários mais estudos sobre a utilização digestiva e metabólica dos nutrientes. Este trabalho teve, portanto, o objetivo de estudar a digestibilidade de dietas e balanços metabólicos de suínos alimentados com dietas que apresentavam diferentes níveis de sorgo baixo tanino em substituição ao milho.

\section{MATERIAL E MÉTODOS}

O experimento foi realizado no Setor de Suinocultura do Departamento de Zootecnia da Universidade Federal de Santa Maria, de agosto a outubro de 2004. Foram utilizados 12 suínos machos castrados, geneticamente homogêneos e irmãos paternos, oriundos de cruzamentos industriais com peso médio inicial de 40,8 quilogramas. Os animais foram alojados em gaiolas metabólicas, semelhantes às descritas por Pekas (1968), mantidas em ambiente controlado a $22^{\circ} \mathrm{C}$. O híbrido do sorgo utilizado foi o BR 305.

$\mathrm{O}$ delineamento experimental utilizado foi $\mathrm{o}$ inteiramente casualizado com três tratamentos (T1 = dieta-controle); $(\mathrm{T} 2=$ substituição de $50 \%$ do milho por sorgo) e (T3 = substituição de $100 \%$ do milho por sorgo). Cada tratamento teve quatro repetições, tendo o animal como unidade experimental. As dietas experimentais foram formuladas para atender às exigências nutricionais sugeridas pelo Nutrient... (1998). A composição das dietas experimentais é apresentada na Tab. 1. O experimento teve duração de 12 dias (sete de adaptação dos animais às gaiolas e ao alimento; cinco dias de coleta). A quantidade diária de ração foi ajustada ao ganho médio diário esperado, considerando um consumo de 2,6 vezes a mantença estimada em $250 \mathrm{kcal} \mathrm{EM} / \mathrm{kg}^{0}{ }^{60}$ (Noblet et al., 1993). O alimento foi distribuído em três refeições diárias, às 8, 13 e 18 horas e o acesso à água foi livre.

Foi utilizado o método de coleta total de fezes, sendo o início e o fim determinados pelo aparecimento de fezes marcadas (foi adicionado $1,5 \%$ de $\mathrm{Fe}_{2} \mathrm{O}_{3}$ às dietas). As fezes foram coletadas a cada $12 \mathrm{~h}$, acondicionadas em sacos plásticos e conservadas em congelador a $-10^{\circ} \mathrm{C}$. No final do experimento as fezes foram homogeneizadas e amostradas $(0,5 \mathrm{~kg})$, secas em estufa de ventilação forçada $\left(60^{\circ} \mathrm{C}\right.$ por $\left.72 \mathrm{~h}\right)$ e moídas para análises posteriores. A urina excretada foi drenada para baldes plásticos com $25 \mathrm{ml}$ de $\mathrm{HCl} 6 \mathrm{~N}$. A cada $12 \mathrm{~h}$, após homogeneização, o volume e a massa eram medidos e uma amostra de $5 \%$ foi retirada e conservada sob refrigeração $\left(4^{\circ} \mathrm{C}\right)$. As análises químicas das fezes e urina foram realizadas segundo metodologia da Official... (1990) 
Tabela 1. Ingredientes e composições analisadas e calculadas das dietas experimentais

\begin{tabular}{|c|c|c|c|}
\hline \multirow{2}{*}{ Ingredientes $^{1}(\%)$} & \multicolumn{3}{|c|}{ Nível de substituição do milho por sorgo (\%) } \\
\hline & 0 & 50 & 100 \\
\hline Milho & 71,58 & 34,37 & - \\
\hline Sorgo & - & 35,79 & 68,76 \\
\hline Farelo de soja & 23,78 & 24,39 & 25,05 \\
\hline Óleo vegetal & 1,64 & 2,44 & 3,19 \\
\hline Premix $^{2}$ & 3,00 & 3,00 & 3,00 \\
\hline Total & 100,00 & 100,00 & 100,00 \\
\hline \multicolumn{4}{|l|}{ Valores calculados } \\
\hline Energia Metabolizável, kcal/kg & 3.265 & 3.265 & 3.265 \\
\hline Proteína Bruta \% & 16,03 & 16,00 & 16,00 \\
\hline Cálcio \% & 0,64 & 0,64 & 0,65 \\
\hline Fósforo \% & 0,50 & 0,51 & 0,52 \\
\hline Lisina $\%$ & 0,84 & 0,84 & 0,85 \\
\hline Metionina \% & 0,28 & 0,27 & 0,27 \\
\hline Treonina $\%$ & 0,66 & 0,66 & 0,67 \\
\hline Triptofano $\%$ & 0,19 & 0,21 & 0,22 \\
\hline Sódio \% & 0,17 & 0,16 & 0,16 \\
\hline \multicolumn{4}{|l|}{ Valores analisados ${ }^{3}$} \\
\hline Energia bruta kcal/kg & 3945 & 3992 & 4037 \\
\hline Proteína bruta \% & 18,14 & 18,53 & 18,95 \\
\hline Fósforo disponível \% & 0,74 & 0,67 & 0,67 \\
\hline Fibra Bruta, \% & 4,66 & 4,42 & 4,52 \\
\hline Extrato Etéreo \% & 8,44 & 7,81 & 8,89 \\
\hline
\end{tabular}

${ }^{\mathrm{T}}$ Matéria natural; ${ }^{2}$ Conteúdo por kg de ração: Vit. A, 228.570UI; Vit. D3, 34.290 UI; Vit. E, 570mg; Vit. K3, 71mg; Vit. B1, 29mg; Vit. B2, 115mg; Vit. B6, 57mg; Vit. B12, 570mcg; Ác. Nicotínico, 715mg; Ác. Pantotênico, 290mg; Biotina, 1.43mg; Ác. Fólico, 17mg; Selênio, 15mg; Colina, 6.860mg; Lisina, 11.430mg; Antioxidante, 17mg; Iodo, 23mg; Cobalto, 13mg; Cobre, 2.500mg; Zinco, 2.200mg; Ferro, 2.000mg; Manganês, 1.100mg; Ca., 180g; P, 64g; $\mathrm{Na}, 44 \mathrm{~g} .{ }^{3}$ Matéria seca

Para o estudo de digestibilidade, foram estimados os coeficientes de digestibilidade aparente da matéria seca $\left(\mathrm{CD}_{\mathrm{a}} \mathrm{MS}\right)$, energia bruta $\left(\mathrm{CD}_{\mathrm{a}} \mathrm{EB}\right)$, proteína bruta $\left(\mathrm{CD}_{\mathrm{a}} \mathrm{PB}\right)$ e energia metabolizável aparente (EMa). Para o estudo metabólico, as variáveis avaliadas foram: nitrogênio (ingestão, excreções fecal/urinária e retenção), energia (ingestão, excreções fecal/urinária e retenção). Os valores de $\mathrm{CD}_{\mathrm{a}} \mathrm{MS}$, $\mathrm{CD}_{\mathrm{a}} \mathrm{EB}, \mathrm{CD}_{\mathrm{a}} \mathrm{PB}$, e $\mathrm{EM}_{\mathrm{a}}$ foram determinados de acordo com metodologia proposta por Matterson et al. (1965). Os dados obtidos foram submetidos à análise de variância pelo emprego do Minitab (Mckenzie e Goldman, 1999). As diferenças entre as médias foram comparadas pelo teste de Tukey.

\section{RESULTADOS E DISCUSSÃO}

A composição química analisada do sorgo (base MS) foi de $8,4 \%$ de PB, 3,7\% de EE e 2,3\% de FB. Se comparados aos valores do Nutrient...
(1998), a PB foi $8,7 \%$ menor e o EE $21,6 \%$ maior. Aspectos genéticos e ambientais são responsáveis por essa variação de composição química do sorgo, principalmente da proteína (Serna-Saldivar e Rooney, 1995).

Os resultados de digestibilidade das dietas são apresentados na Tab. 2. Em relação à dietacontrole, a substituição de $50 \%$ do milho por sorgo não influenciou $(\mathrm{P}>0,05)$ as digestibilidades da MS, PB e EB. No entanto, as digestibilidades da dieta com $50 \%$ de substituição em relação à dieta com $100 \%$ de sorgo, foram maiores $(\mathrm{P}<0,05)$ em $5 \%$ para a proteína e $4 \%$ para energia. As digestibilidades foram menores $(\mathrm{P}<0,05)$ em $3 \%$ para a matéria seca, $8 \%$ para proteína e $5 \%$ para energia bruta quando o milho foi substituído totalmente por sorgo, em relação à dieta-controle. A metabolizibilidade da energia bruta não diferiu entre os tratamentos. 
Tabela 2. Digestibilidade aparente e metabolização da energia bruta de dietas para suínos com três níveis de substituição de milho por sorgo

\begin{tabular}{lccccc}
\multicolumn{1}{c}{ Variáveis } & \multicolumn{2}{c}{ Níveis de substituição de milho por sorgo (\%) } & \multirow{2}{*}{ dpr $^{1}$} & \multirow{2}{*}{$\mathrm{P}^{2}$} \\
\cline { 2 - 3 } & 0 & 50 & 100 & & \\
\cline { 2 - 4 } Coeficientes de digestibilidade & & & & & \\
Matéria seca \% & $85,49 \mathrm{a}$ & $84,96 \mathrm{ab}$ & $82,61 \mathrm{~b}$ & 1,29 & 0,026 \\
Proteína bruta \% & $82,80 \mathrm{a}$ & $80,84 \mathrm{a}$ & $76,56 \mathrm{~b}$ & 2,11 & 0,007 \\
Energia bruta \% & $83,37 \mathrm{a}$ & $82,64 \mathrm{a}$ & $79,44 \mathrm{~b}$ & 1,62 & 0,017 \\
\hline Coeficiente de metabolização & & & & & \\
Energia bruta \% & 85,37 & 85,18 & 84,62 & 1,11 & 0,622 \\
\hline
\end{tabular}

Valores seguidos por letras distintas na linha, diferem entre si pelo teste de Tukey .

${ }^{1}$ dpr: desvio-padrão residual; ${ }^{2}$ P: nível de significância $5 \%$

A substituição de níveis crescentes de milho por sorgo não altera a digestibilidade da proteína bruta (Fialho et al., 2002), matéria seca e energia bruta (Lin et al., 1987). Estes resultados são diferentes dos obtidos neste estudo, onde se observou que a substituição total do milho por sorgo diminuiu significativamente a digestibilidade aparente dos componentes nutricionais das dietas. Como os grânulos de amido do sorgo e do milho são semelhantes em tamanho, forma e composição, a principal diferença entre os dois cereais está no tipo e distribuição das proteínas ao redor do amido do endosperma (Rooney e Pflugfelder, 1986). O sorgo geralmente apresenta uma proporção da região periférica do endosperma maior do que a do milho (Rooney e Miller, 1982). Esta região periférica é densa e resistente à penetração de água, sendo constituída de elevado conteúdo protéico que também pode prejudicar a degradação física e enzimática do amido. Além disso, as prolaminas presentes no sorgo podem formar ligações entre si e diminuir a digestibilidade do amido e da proteína que o envolve (Rooney e Pflugfelder, 1986). As diferenças de estrutura e tipo de proteína do grão de sorgo, comparadas às do milho, podem ter contribuído para a menor digestibilidade verificada quando se substituiu integralmente o milho pelo sorgo. A presença de fatores antinutricionais no sorgo, como taninos, ácidos fenólicos e flavonóides também podem ter contribuído negativamente na digestibilidade dos nutrientes.

O balanço do $\mathrm{N}$ é apresentado na Tab. 3. Na dieta com substituição de $50 \%$ de sorgo, o balanço de $\mathrm{N}$ não diferiu $(\mathrm{P}>0,05)$ das dietas-controle e com substituição total.

Tabela 3. Balanço do nitrogênio de dietas para suínos com três níveis de substituição de milho por sorgo

\begin{tabular}{|c|c|c|c|c|c|}
\hline \multirow{2}{*}{ Variáveis } & \multicolumn{3}{|c|}{ Níveis de substituição de milho por sorgo (\%) } & \multirow{2}{*}{$\mathrm{dpr}^{1}$} & \multirow{2}{*}{$\mathrm{P}^{2}$} \\
\hline & 0 & 50 & 100 & & \\
\hline \multicolumn{6}{|l|}{ Nitrogênio } \\
\hline Ingerido $\mathrm{g} / \mathrm{dia}$ & 49,81 & 48,75 & 49,15 & 1,22 & 0,492 \\
\hline Fecal g/dia & $8,57 \mathrm{a}$ & $9,34 \mathrm{ab}$ & $11,55 \mathrm{~b}$ & 1,21 & 0,018 \\
\hline Urinário g/dia & 5,96 & 4,13 & 6,43 & 4,36 & 0,741 \\
\hline Retido g/dia & 35,29 & 35,28 & 31,17 & 4,94 & 0,431 \\
\hline Absorvido g/dia & $41,24 \mathrm{a}$ & $39,41 \mathrm{ab}$ & $37,60 \mathrm{~b}$ & 1,03 & 0,002 \\
\hline Retido/absorvido \% & 85,43 & 89,35 & 82,89 & 11,37 & 0,729 \\
\hline
\end{tabular}

Valores seguidos por letras distintas na linha, diferem entre si pelo teste Tukey .

${ }^{1} \mathrm{dpr}$ : desvio-padrão residual; ${ }^{2} \mathrm{P}$ : nível de significância $5 \%$

A excreção fecal de $\mathrm{N}$ foi $25 \%$ maior $(\mathrm{P}<0,05)$ e a absorção $10 \%$ menor $(\mathrm{P}<0,05)$ nos animais alimentados com substituição total do milho por sorgo, comparado à dieta-controle. Não houve diferença significativa $(\mathrm{P}>0,05)$ para o $\mathrm{N}$ retido entre os tratamentos. A excreção fecal de $\mathrm{N} \mathrm{em}$ suínos em crescimento, alimentados com dietas à base de sorgo, aumenta significativamente em relação a dietas que usam milho, mas a absorção e a retenção não se alteram (Fent et al., 2001). A substituição do sorgo em dietas para suínos na mesma fase, não altera a excreção fecal e absorção de N, mas determina retenção $39 \%$ menor e excreção urinária $27 \%$ 
maior, comparada a dietas que usam milho (Lin et al., 1987). Esses trabalhos demonstram que o sorgo tem componentes que influem não só na digestibilidade do $\mathrm{N}$, mas também na sua metabolizabilidade. No presente estudo, houve diferença apenas na digestibilidade do $\mathrm{N}$ quando o milho foi substituído totalmente pelo sorgo. Alguns fatores como genética (alto ou baixo tanino), natureza e distribuição das proteínas no sorgo podem influenciar no balanço do nitrogênio. O tanino (Flavan 3-4 diol) pode interagir e se complexar com proteínas e formar compostos insolúveis, prejudicar a ação enzimática na hidrólise protéica e reduzir a digestibilidade (Duodu et al., 2003).

Com relação a distribuição protéica no grão de sorgo, aproximadamente $80 \%$ estão no endosperma (Taylor e Schussler, 1986). As principais proteínas do endosperma são as prolaminas, classificadas de acordo com sua estrutura, peso molecular e solubilidade em $\alpha, \beta$ e $\gamma$-kafirinas (Shull et al., 1991). As kafirinas $\gamma$ e $\beta$ podem apresentar ligações cruzadas e formar estrutura resistente à ação enzimática, retardar a digestão da $\alpha$-kafirina, que representa $80 \%$ de proteína do grão (Oria et al., 1995). A adesão entre o amido do endosperma e a proteína é mais forte no sorgo que no milho e pode influenciar a digestibilidade dos nutrientes (Rooney e Pflugfelder, 1986). Em cultivares de sorgo com baixo tanino, como o utilizado neste estudo, a excreção de $\mathrm{N}$ é influenciada ainda pela ação conjunta ou isolada de fatores como o tipo de proteína, sua localização e interações no interior do grão e compostos antinutricionais.

Os resultados da energia ingerida e excretada (fecal e urinária) e energia metabolizável das dietas são apresentados na Tab. 4. A excreção fecal foi $15 \%$ maior $(\mathrm{P}<0,05)$ para os animais alimentados com dietas onde o milho foi substituído totalmente pelo sorgo, em relação à dieta-controle. No entanto, a excreção de energia urinária não diferiu $(\mathrm{P}>0,05)$ entre os tratamentos. Não houve diferença significativa $(\mathrm{P}>0,05)$ para a energia metabolizável entre as dietas. A substituição total do milho pelo sorgo em dietas para suínos aumentou a excreção fecal e diminuiu a energia metabolizável em relação às dietas que continham milho (Fent et al., 2001). A utilização de sorgo com baixo tanino em substituição ao milho para suínos em crescimento não altera a energia metabolizável das dietas (Cousins et al., 1981, Rodrigues et al., 2002). A estrutura da matriz protéica e a magnitude de sua união ao endosperma do grão de sorgo podem dificultar a exposição dos grânulos de amido e a ação da amilase salivar (Rooney e Pflugfelder, 1986). Estes fatores podem explicar os resultados da maior excreção fecal de energia nas dietas com substituição total de milho por sorgo neste estudo.

Tabela 4. Ingestão, excreção fecal e urinária e energia metabolizável das dietas para suínos que contêm três níveis de substituição de milho por sorgo

\begin{tabular}{|c|c|c|c|c|c|}
\hline \multirow[t]{2}{*}{ Variáveis } & \multicolumn{3}{|c|}{$\begin{array}{l}\text { Níveis de substituição de milho por } \\
\text { sorgo }(\%)\end{array}$} & \multirow[t]{2}{*}{$\mathrm{dpr}^{1}$} & \multirow[t]{2}{*}{$\mathrm{P}^{2}$} \\
\hline & 0 & 50 & 100 & & \\
\hline \multicolumn{6}{|l|}{ Energia } \\
\hline Ingerida kcal/dia & 6556 & 6492 & 6600 & 163 & 0,652 \\
\hline Fecal kcal/dia & $1206 a$ & $1223 \mathrm{ab}$ & $1425 b$ & 103 & 0,008 \\
\hline Urinária kcal/dia & 55 & 38 & 59 & 40 & 0,741 \\
\hline Metabolizável kcal/dia & 5412 & 5327 & 5181 & 143 & 0,122 \\
\hline
\end{tabular}

Valores seguidos por letras distintas na linha, diferem entre si pelo teste Tukey .

${ }^{1}$ dpr: desvio-padrão residual; ${ }^{2} \mathrm{P}$ : nível de significância $5 \%$

\section{CONCLUSÕES}

A substituição de milho por sorgo em dietas para suínos em crescimento pode ser feita, sem comprometer a digestibilidade e metabolização dos nutrientes, em até $50 \%$ do volume.

\section{AGRADECIMENTOS}

Os autores agradecem ao Conselho Nacional para o Desenvolvimento Científico e Tecnológico (CNPq) e a Comissão de Aperfeiçoamento de Pessoal de Ensino Superior (CAPES) pelas bolsas concedidas. A J.H.S. Silva e G.G. Garcia pela colaboração. 


\section{REFERÊNCIAS BIBLIOGRÁFICAS}

ASQUITH, T.N.; BUTLER, L.C. Interaction of condensed tannins with selected proteins. Phytochemistry, v.25, p.1591-1593, 1986.

COUSINS, B.W.; TANKSLEY, T.D.; KNABE, D.A. et al. Nutrient digestibility and performance of pigs fed sorghums varying in tannin concentration. J. Anim. Sci., v.53, p.1524-1537, 1981.

DUODU, K.G.; TAYLOR JR., N.; BELTON, P.S. et al. Factors affecting sorghum protein digestibility. J. Cereal Sci., v.38, p.117-131, 2003.

FENT, R.W.; CARTER, S.D.; RINCKER, M.T. et al. Energy and nitrogen balance of pigs fed commercial red sorghum, identity-preserved white sorghum, or corn, 2001. Disponível em: http://www.ansi.okstate.edu/research/2001 rr/40/40. htm. Acessado em 22 mar. 2005.

FIALHO, E.T.; LIMA, J.A.F.; OLIVEIRA, W. et al. Substituição do milho pelo sorgo sem tanino em rações de leitões: digestibilidade dos nutrientes e desempenho animal. Rev. Bras. Milho Sorgo, v.1, p.105-111, 2002.

LIN, F.D.; KNABE, D.A.; TANKSLEY JR., T.D. et al. Apparent digestibility of amino acids, gross energy and starch in corn, sorghum, wheat, barley, oat, groats and wheat middlings for growing pigs. $J$. Anim. Sci., v.64, p.1655-1663, 1987.

LOPES, A.B.R.C. Silagem de grãos úmidos de sorgo com alto e baixo tanino para suínos em fase inicial. 2004. 125f. Tese (Doutorado em Zootecnia) - Universidade Estadual Paulista, Botucatu, 2004.

MARISCAL-LANDÍN, G.; AVELLANEDA, J.H.; REIS de SOUZA, T.C. et al. Effect of tannins in sorghum on amino acid ileal digestibility and on trypsin (E.C.2.4.21.4) and chymotrypsin (E.C.2.4.21.1) activity of growing pigs. Anim. Feed Sci. Technol., v.117, p.245-264, 2004.

MATTERSON, L.D.; POTTER, L.M.; STUTS, M.W. et al. The metabolizable energy of feed ingredients for chickens. Stors: Connecticut, the University of Connecticut. Agricultural Experiment Station. 1965. 11p. (Research Report).

MCKENZIE, J.; GOLDMAN, R.N. The Student Edition of Minitab for Windows Manual: Release 12. Belmont: Addison-Wesley Longman, Incorporated: Softcover, 1999. 592p.
NOBLET, J.; SHI, X.S.; DUBOIS, S. et al. Metabolic utilization of dietary energy and nutrients for maintenance energy requirements in sows: basis for a net energy system. Br. J. Nutr., v.70, p.407419, 1993.

NUTRIENT requirements of swine. 10.ed. Washington : National Academy, 1998. 189p.

OFFICIAL methods of anlysis. 15.ed. Arlington, VA: AOAC, 1990. 1117p.

ORIA, M.P.; HAMAKER, B.R.; SHULL, J.M. Resistence of sorghum $\alpha, \beta$, and $\gamma$ - kafirins to pepsin digestion. J. Agric. Food Chem., v.43, p.2148-2153, 1995.

PEKAS, J.C. Versatible swine laboratory apparatus for physiologic and metabolic studies. J. Anim. Sci., v.27, p.1303-1309, 1968.

RODRIGUES, P.B.; FREITAS, R.T.F.; FIALHO, T.E. et al. Digestibilidade dos nutrientes e desempenho de suínos em crescimento e terminação alimentados com rações à base de milho e sorgo suplementadas com enzimas. Rev. Bras. Milho e Sorgo, v.1, p.91-100, 2002.

ROONEY, L.W.; MILLER, F. Variation in the structure and kernel characteristics of sorghum. In: INTERNATIONAL SYMPOSION ON SORGHUM GRAIN QUALITY, 1982, Patancheru, Índia. Proceedings... Patancheru: 1982. p. 143-162.

ROONEY, L. W.; PFLUGFELDER, R. L. Factors affecting starch digestibility with special emphasis on sorghum and corn. J. Anim. Sci., v.63, p.16071623, 1986.

SERNA-SALDIVAR, S.; ROONEY, L.W. Sorghum and millets: chemistry and technology. In: DENDY, D.A. V. (Ed). Structure and chemistry of sorghum and millets. St. Paul: American Association of Cereal Chemists, 1995. p.69-124.

SHULL, J.M.; WATTERSON, J.J.; KIRLEIS, A.W. Proposed nomenclature for the alcoholsoluble proteins (kafirins) of sorghum-bicolor (L. Moench) based on molecular-weight, solubility, and structure. J. Agric. Food Chem., v.39, p.83-87, 1991.

TAYLOR, J.R.N.; SCHUSSLER, L. The protein composition of the different anatomical parts of sorghum grain. J. Cereal Sci., v.4, p.361-369, 1986. 